\title{
Laboratory Investigation to Use Lost Circulation Material in Water Base Drilling Fluid as Lost Circulation Pills
}

\author{
Majid Sajjadian $^{\text {a, Ehsan Esmaeilpour Motlagh }}{ }^{\text {b }}$, Ali Akbar Daya ${ }^{\text {c }}$ \\ ${ }^{a}$ Research Institute of Petroleum Industry Tehran, Iran \\ sajjadian.m@gmail.com \\ ${ }^{\mathrm{b}}$ Research Institute of Petroleum Industry Tehran, Iran \\ ehsanemotlagh@gmail.com \\ ${ }^{c}$ Assistant Professor, department of mining engineering, University of Sistan and Baluchestan \\ aliakbardaya@eng.usb.ac.ir
}

\begin{abstract}
The increase of the demand of oil and also the price causes research in inventing new technology such as non-damaging lost circulation pills (LCP) to produce more oil with less cost. Optimizing the LCP compositions to stop the lost circulation effectively and also protect the production zone from liquid and solids invasion significantly. Key parameters include of Shape, particle size distribution and concentration of the lost circulation materials (LCM) are necessary to determine the effectiveness of LCP.In this study, the Permeability Plugging Apparatus (PPA) is used to evaluate effectiveness of sized calcium carbonates in different concentrations to cure the lost circulation. Ceramic disks with nominal pore sizes 20, 35, 60 microns, are used to simulate lost circulation zones. Spurt loss and filtrate volume are primary parameters to be evaluated in this research.
\end{abstract}

Keywords: Polymer-base drilling fluid, Lost circulation pills, calcium carbonate

\section{INTRODUCTION}

During the drilling operation in highly permeable, highly fractured and low pressured zones; loss of the drilling fluid because of the migration through formation is known as lost of circulation. These days, lost circulation has presented one of the great challenges to the drilling industry, causing great expenditures of cash and time to fighting the problem. Trouble cost for mud losses, wasted rig time, ineffective remediation materials and techniques, and in the worst cases - for lost holes side tracks. The risk of drilling wells in areas known to contain these problematic formations is a key factor in decisions to approve or cancel exploration and development projects. Mainly lost circulation occurs in one of two basic ways; invasion or fracturing.Invasion occurs to the formations that are cavernous, vugular, fractured or unconsolidated. In the dynamic filtration process the pore invasion increases. That is because; the pressure differential increases, the fluid viscosity decreases because of the shear effect and mud cake erodes during trip and circulation.Fracturing is initiated and lost circulation occurs when some critical fracture pressure is reached or exceeded. Once a fracture is created or opened by an imposed pressure, it may be difficult to repair and may never regain the original formation strength. Lost circulation may persist even though the pressure is later reduced. In some cases it is appreciable to reduce the amount of loss instead of loss of the entire volume during drilling. Lost circulation can be classified in three groups as; seepage loss (1-10 bbl/hr), partial loss (10-500 $\mathrm{bbl} / \mathrm{hr}$ ), and complete loss (over $500 \mathrm{bbl} / \mathrm{hr}$ ) (Nayberg and Petty 1986). (1)

There are some researches made to improve lost circulation. At the present day, drilling industry is emphasizing underbalanced drilling (UBD) technology. The reason is the advantage of reducing formation damage and minimizing lost circulation problem that reduce the production of oil and gas reservoirs. It is very difficult to remain in the underbalanced drilling condition because the inaccuracy of pore pressure prediction and the complex nature of water, oil, gas, and solid multiphase flow in the underbalanced system. Also, underbalanced drilling technology needs special equipment and well educated drilling crew. Technical limitation during the appliance of this method is another limitation.

Because of reasons stated above, there are plenty of studies made to solve the lost circulation problems while classical drilling. Pumping LCM as pills is one of the methods to combat lost circulation. Pumping lost circulation plug (LCP) functions, either by forming bridges or increasing 
viscosity of the fluid to limit fluid entrance into the formation. There are many of lost circulation materials that used in the industry; such as oil-soluble resins, fibers acid soluble particulates, graded salt slurries, high concentrated linear and cross linked biopolymers and non-biopolymers (Samuel et al., 2003). (2)

Bridging agents are often used to stop serious fluid loss, and calcium carbonate $\left(\mathrm{CaCO}_{3}\right)$ is the most commonly used. It is the suitable granular type of material because of its mechanical and chemical properties. $\mathrm{CaCO}_{3}$ is resistant to pressure differentials and swap and surge impacts in the wellbore. Its acid solubility allows using it in producing zones. In this study, $\mathrm{CaCO}_{3}$ will be tested as LCM with different particle sizes. The range of particle size distribution of LCM used in this study will be based on the range of materials available in market.In this study, compositions and rheology parameters that depend on pressure-temperature difference, particle size, and pore throat size of lost circulation zones are tested. This study isprovided to carry out an experimental investigation on determining the suitable composition of LCP to optimum lost circulation problem by using calcium carbonate, for fractured and high permeable zones. The results have been compared and a suitable composition has been determined for loss circulation zones with different permeability.Bridging materials are often used to improve unusually lost circulation to the formation and formation damage because of fine solid invasion. Regular drilling fluid systems have large quantities of fine solids that invade to the formation causing damage in productive zones. The main components of these drilling muds are barite and bentonite. An internal block within the formation is created which cannot be removed while barite invades the productive zones (Marqez 1996). (3)

During form an external filter cake, especially fine solids are forced into the formation, to builde an internal filter cake. An internal filter cake plugs the near surface pore and reduces the formation permeability. Fine particles penetrate deeper into the pores and are not easily removed by acidizing stimulation.Invasion of larger particles is usually localized to near surface. Studies conducted by Bailey et al. (1999) showed a strong correlation between invasion and damage. Due to this, minimizing of internal filter cake and quickly forming of external cake is very important for both fluid loss and formation damage control. A semi permeable external filter cake can significantly reduce the invasion of the solids and the filtrate. (4)

$\mathrm{CaCO}_{3}$ (Figure 1) is the most commonly used, granular type of LCM's. It is a bridging material with proper mechanical and chemical characteristics to be utilized in the production

zones. Its thermal and mechanical resistance makes the formed mud cake in the wellbore to have mechanical consistency that stands impact and high-pressure differentials. $\mathrm{CaCO}_{3}$ particulates, if not removed will remain in the wellbore or formation and permanently impair the productivity of well.

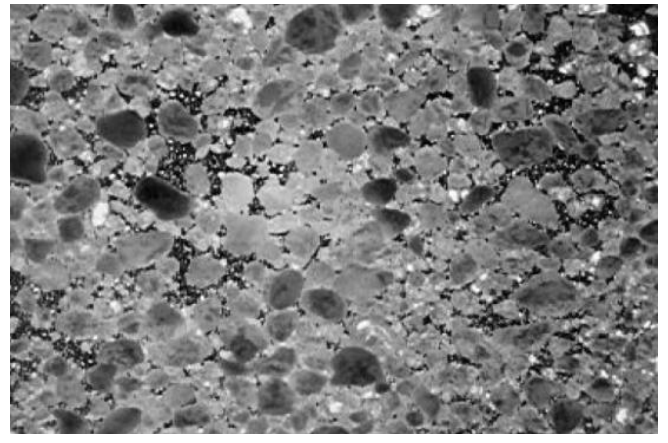

Figure1. Calcium Carbonate (Verret et al., 2000)

Hence, additional treatments should be applied to remove these particulates. Chemically, it is acid soluble so it can be removed from the porous matrix to recover the permeability of the rock by $\mathrm{HCl}$ washes.Salt pills are also granular type of material and they do not need additional treatment like acidizing unlike $\mathrm{CaCO}_{3}$ pills. However they are less effective in controlling losses and are more difficult to design due to solubility issues (Rosato and Supriyono, 2002).(4)

\section{EXPERIMENTAL}

\subsection{Materials}

Permeability Plugging Apparatus is used as filtration device to provide information about investigation of different sizes of $\mathrm{CaCO}_{3}$. 
PPA (Figure2) is a high pressure and high temperature (HPHT) filtrationdevice is used in the experiments. Ceramic disks (Figure 3) are used as afiltration medium. They have wide range of permeability and porosities tosimulate fractured zones accurately. The equipment's limitation is 5000 psi forpressure and $500{ }^{\circ} \mathrm{F}\left(260{ }^{\circ} \mathrm{C}\right)$ for temperature. If the test temperature exceeds $200{ }^{\circ} \mathrm{F}$, back pressure must be applied to the cell to prevent boiling. For backpressure non-flammable, $\mathrm{CO}_{2}$ is used. The filtration cell has a capacity of $300 \mathrm{ml}$. Hydraulic Pressure is applied to the cell by a hand pump. The filtration iscollected out on the top. Collecting the filtrate out on the top avoid faultyreadings due to the settling of particles during the static test from contributing tothe buildup of filtration cake. (5)

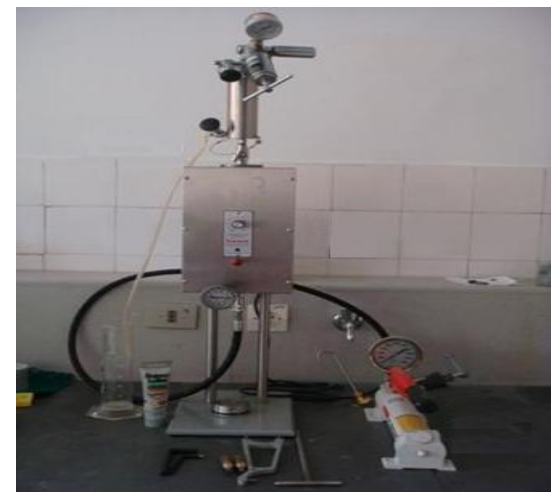

Figure2. Permeability Plugging Apparatus (PPA)

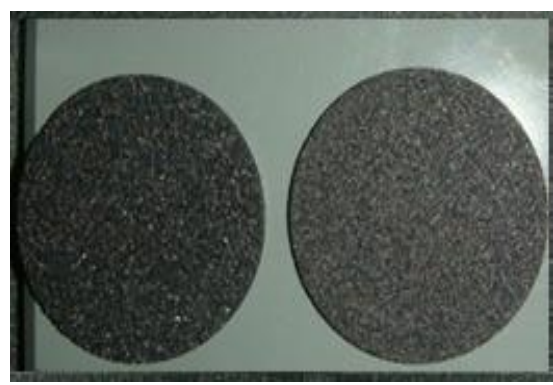

Figure3. Ceramic Disks (left to right $35 \mu, 60 \mu$ )

\subsection{Experimental Procedure}

In experimental work there are several steps need to be followed. First is to findparticle sizes of LCM and pore size distributions of the ceramic disks, to determine the combinations of LCP and ceramic disks combination for experiments. Following this step LCPs' are prepared and permeability plugging tests are run. Finally the ceramic disks and filtration tests results are examined to see the effect of the selected LCP and pore sizes.

PPT is run:

1. Specific ceramic disk is placed in the PPA cell and pour $275 \mathrm{ml}$ of LCPinto the cell.

2. Adjust the pressure to $300 \mathrm{psi}$ and temperature to $75^{\circ} \mathrm{F}$.

3. If the test is run above the boiling point the back pressure must be applied.

4. Collect filtrate for 30 minute. Record the reading at 7.5 minute as spurt loss EV7.5 and after 30 minute as total volume EV30.

5. Disassemble the cell and remove the ceramic disk. (6)

After finishing the PPT estimation filtration parameters can be calculated (Daviset al., 1999) from the data collected at 7.5 and 30 minute intervals. Spurt lossTotal filtration and static filtration parameters are calculated by using theequations below:

Spurt Loss, $m l=2 \times[E V 7.5-(E V 30-E V 7.5)]$

Total Fluid Loss $=2 \times$ EV30

\subsection{Preparation of Drilling Fluid (LCP)}

Solids free viscous pills are used in the experiments. FLO-PROTM is used for LCP. The LCP is prepared with $350 \mathrm{cc}$ pure water, $1 \mathrm{lb} / \mathrm{bbl} \mathrm{XC}$ polymer, $4 \mathrm{lb} / \mathrm{bbl}$ modified starch and of $\mathrm{CaCO}_{3}$. First, 
$\mathrm{XC}$ polymer and modified starch are added to the fresh water and mixed for 30 minutes. $\mathrm{CaCO}_{3}$ is added and mixed for 5 more minutes. Hamilton beech mixer is used for preparation of LCP.

\subsection{Mud Rheology Test}

All the drilling mud composition was made. Prior to PPT test, the property of drilling fluid systems was obtained by rheology test. The required quantity of carbonate calcium was added to the drilling mud composition and stirred at high speed for $30 \mathrm{~min}$. Then, the rheological property of the treated drilling mud composition was measured using a FANN model 35 type rotating viscosimeter. The rheological parameters such as apparent viscosity, plastic viscosity, Gel $10 \mathrm{sec}$. and Gel $10 \mathrm{~min}$. can be determined. (6)

\section{RESUltS AND DISCUSSION}

\subsection{Permeability Plugging Tests}

In order to show the effect of $\mathrm{CaCO}_{3}$ on filtration properties, PPA filtration tests were conducted. some experiments in total were carried out during this study.Tests are conducted at $75^{\circ} \mathrm{F}$ of constant temperature and 300 psi of constant differential pressure.

\subsection{Effect of $\mathrm{CaCO}_{3}$ concentration}

For determining the effect of the $\mathrm{CaCO}_{3}$ concentration, bridging material was varied from $10 \mathrm{lb} / \mathrm{bbl}$ to $30 \mathrm{lb} / \mathrm{bbl}$ for different ceramic disk. The properties of the fluids are shown on table 1.

Table1. Properties of Lost Circulation Plugs

\begin{tabular}{|c|l|l|l|}
\hline concentration & $\mathrm{CaCO}_{3}(10 \mathrm{ppb})$ & $\mathrm{CaCO}_{3}(20 \mathrm{ppb})$ & $\mathrm{CaCO}_{3}(30 \mathrm{ppb})$ \\
\hline $\mathrm{PV}, \mathrm{cP}$ & 7.5 & 7.5 & 7.5 \\
\hline $\mathrm{YP}, \mathrm{lb} / 100 \mathrm{ft}^{2}$ & 16 & 15.5 & 16.5 \\
\hline $\begin{array}{c}\text { Gel } 10 \mathrm{sec} . \\
\mathrm{b} / 100 \mathrm{ft}^{2}\end{array}$ & 9 & 8.5 & 9.5 \\
\hline $\begin{array}{c}\text { Gel } 10 \mathrm{~min} . \\
\mathrm{lb} / 100 \mathrm{ft}^{2}\end{array}$ & 11 & 10.5 & 11.5 \\
\hline Density, ppg & 8.7 & 7.1 & 7.2 \\
\hline API Filtrate $\mathrm{ml}$ & 7.4 & 6.95 & 7.3 \\
\hline $\mathrm{pH}$ & 8.5 & 8.5 & 8.5 \\
\hline
\end{tabular}

Concentration of $\mathrm{CaCO}_{3}$ has a significant effect on spurt loss and total filtrationand static filtration rate. The test results are demonstrated by spurt loss and totalFiltration rate vs. concentration graphs for bridging materials. The results are shown on figures 4,5 .

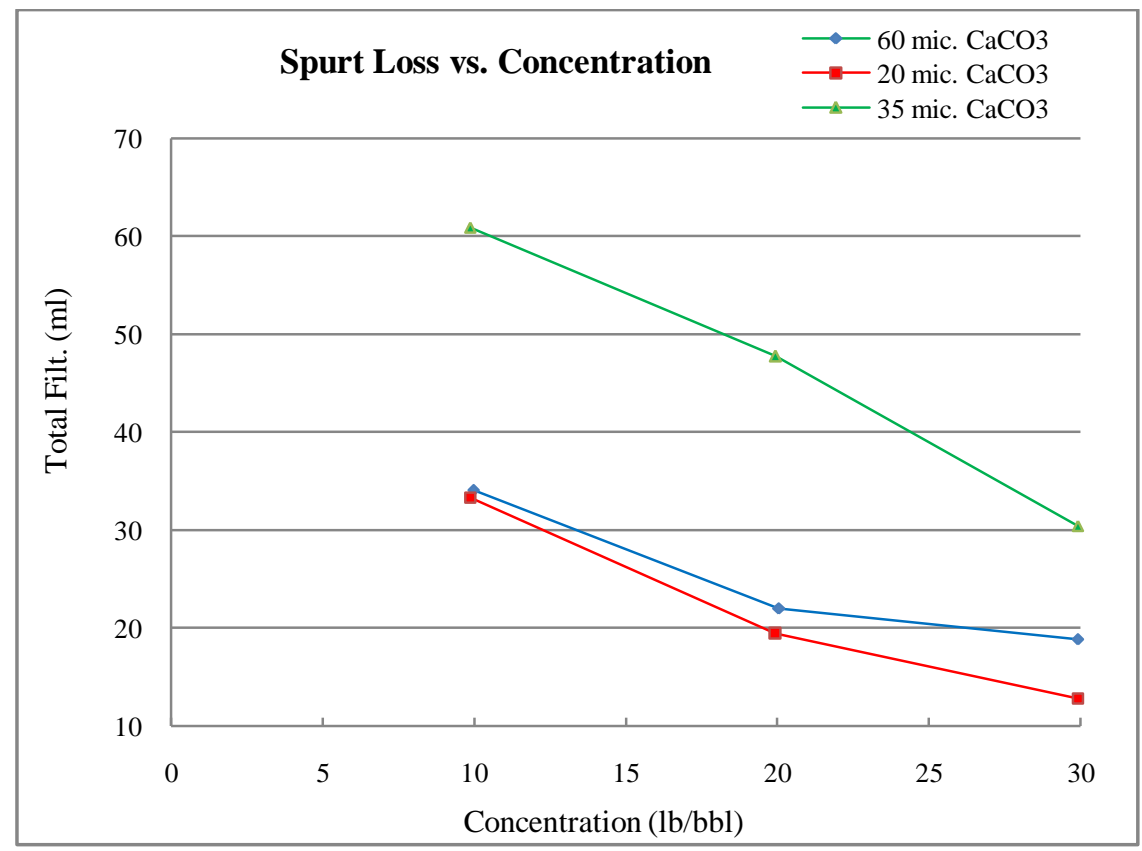

Figure4. Spurt Loss vs. Concentration 


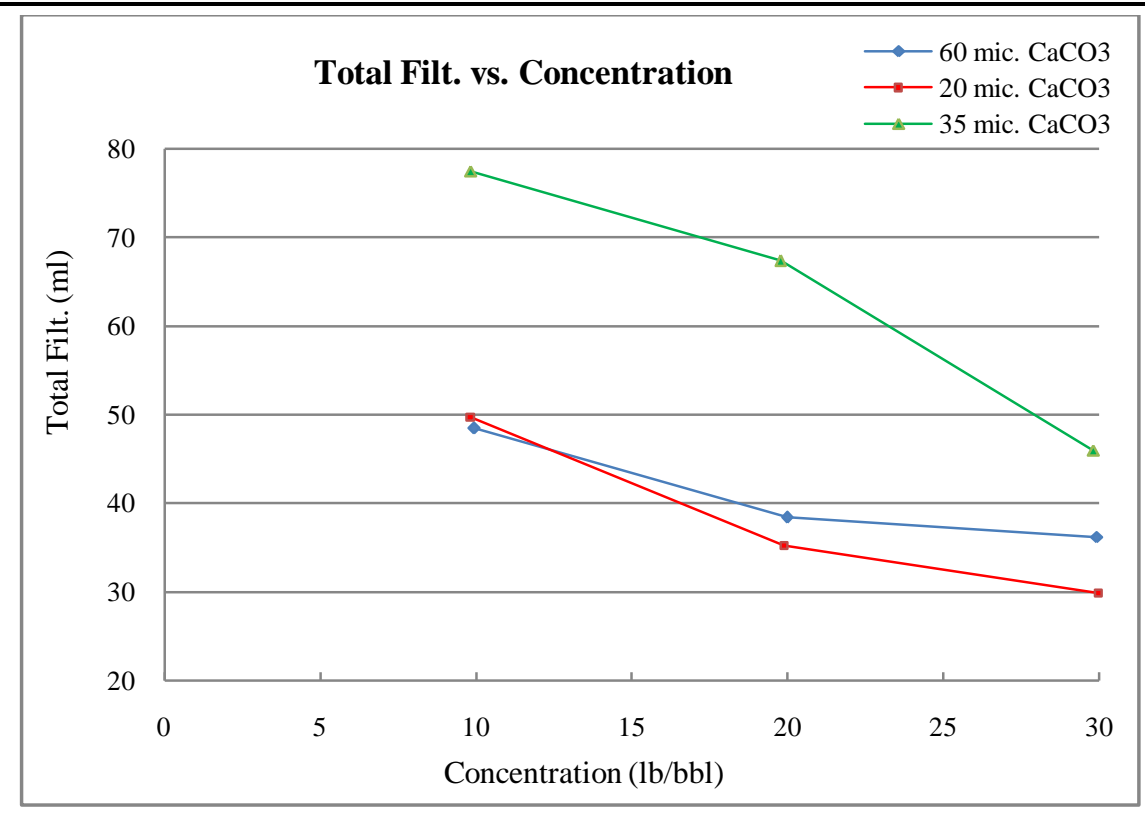

Figure5. Total Loss vs. Concentration

For $60 \mu$ ceramic disks, the higher concentration has better sealing capacity moreover as the pore size increases effect of concentration is clearer.On the other hand, for $20 \mu$ and $35 \mu$ ceramic disks filtration parameters increases as the concentration of the bridging material is increased from $10 \mathrm{lb} / \mathrm{bbl}$ to 30 $\mathrm{lb} / \mathrm{bbl}$. The reason is the particle size of the $\mathrm{CaCO}_{3}$ is bigger than the mean pore size diameter of ceramic disks. For all of the ceramic disk reduction of concentration from $30 \mathrm{lb} / \mathrm{bbl}$ to $20 \mathrm{lb} / \mathrm{bbl}$, an increase in total filtration and spurt loss is occurred. The deposition of thin cake also shows the lack of bridging particles to form a suitable cake. $30 \mathrm{lb} / \mathrm{bbl}$ of bridging agent concentrations are appropriate for spurt loss and total filtration for 20,35 and 60 micron ceramic disks. Thin, impermeable mud cake is formed. Although it does not provide lowest values of filtration, it is the optimum amount when filter cake properties is considered. The lowest spurt lost and total filtration is observed for this particle size distribution of the bridging material.

\section{Conclusions}

During this study, performance of $\mathrm{CaCO}_{3}$ is tested as a LCM in polymer base mud. Different concentrations of $\mathrm{CaCO}_{3}$ are tested for plugging tests using ceramic disk as filtration medium. The results are analyzed and the following conclusions can be drawn from the study:

- Concentration of the LCM is affecting sealing capacity of LCP. Whereas; it is not appropriate for all cases to state that, as the concentration of $\mathrm{CaCO}_{3}$ increases, sealing capacity of LCP develops.

- For some cases especially smaller pore sizes with larger bridging materials concentration should be optimized.

- Permeability plugging tests illustrative equipment for studying the effect of lost circulation plugs. Photographs taken after the tests reveals the smaller filtration values obtained for maximum sealing.

- For $60 \mu$ ceramic disks $\mathrm{CaCO}_{3}$ has provided better solution than other sizes of bridging agents.

\section{ACKNOWLEDGEMENTS}

The authors would like to thank exploration directorate for supporting to publish this paper.

\section{REFERENCES}

[1] Abrams, A.: "Mud Design to Minimize Rock Impairment due to Particle Invasion," Journal Petroleum Technology, May 1977, 586-592.

[2] Alajmi, S.E. and Schubert, J. J. "Optimum selection of Underbalanced techniques" paper SPE/IADC 85322 presented at the 2003 SPE/IADC Middle East Drilling Technology Conference and held in Abu Dhabi, U.A.E., 20-22 October 2003. 
[3] Bugbee, J. M.: "Lost Circulation-A Major Problem in Exploration and Development", paper presented at the spring meeting of Southwestern District, Division of Production, Forth Worth, Texas (March 1953)

[4] Cargnel, R.D. and Luzardo, J.P.: "Particle Size Distribution Selection of $\mathrm{CaCO}_{3}$ in Drill-In Fluids: Theory and Applications," paper SPE 53937 presented at the 1999 SPE Latin American and Caribbean Petroleum Engineering Conference, Caracas, Venezuela, 21-23 April 1999.

[5] Ross, C.M., Williford, J. and Sanders, M.W.: "Current Materials and Devicesfor Control of Fluidloss," paper SPE 54323 presented at the Asia Pacific Oiland Gas Conference and Exhibition, Jakarta, Indonesia, 20-22 April 1999.

[6] Nayberg, T. M. And Petty, B. R.: "Laboratory study of Lost Circulation materials for use in both oil-base and water-base drilling muds" IDAC/SPE 14723 10-12 February 1986. 